2019-07-19

\title{
Compressive stress-strain relationship for fly ash concrete under thermal steady state
}

Fan, $\mathrm{K}$

http://hdl.handle.net/10026.1/14667

10.1016/j.cemconcomp.2019.103371

Cement and Concrete Composites

Elsevier

All content in PEARL is protected by copyright law. Author manuscripts are made available in accordance with publisher policies. Please cite only the published version using the details provided on the item record or document. In the absence of an open licence (e.g. Creative Commons), permissions for further reuse of content should be sought from the publisher or author. 


\title{
Compressive stress-strain relationship for fly ash concrete
}

\section{under thermal steady state}

\author{
Kunjie Fan $^{\mathrm{a}, \mathrm{b}, *}$, Dawang $\mathrm{Li}^{\mathrm{a}, \mathrm{b}}$, Nattapong Damrongwiriyanupap ${ }^{\mathrm{c}}$, \\ Long-yuan $\mathrm{Li}^{\mathrm{b}}$
}

${ }^{a}$ Guangdong Provincial Key Laboratory of Durability for Maine Civil Engineering, Shenzhen University, Shenzhen 518060, China

${ }^{\mathrm{b} S c h o o l}$ of Engineering, University of Plymouth, Plymouth PL4 8AA, UK

'Department of Civil Engineering, School of Engineering, University of Phayao, Phayao 56000,

Thailand

\section{Abstract}

The paper presents an experimental study on the mechanical properties of fly ash concrete during thermal exposure. The tests were carried out on an apparatus specially designed for studying "hot" mechanical properties of concrete materials. The results presented include the compressive strength, strain at peak stress point, Young's modulus, and stress-strain relation at temperature ranging from ambient to $900{ }^{\circ} \mathrm{C}$. It was found that $25 \%$ replacement of ordinary Portland cement with fly ash in concrete would yield less decrease of compressive strength and more linear stress-strain response at high temperatures due to the further reaction between the reactive silica in fly ash and calcium hydroxide under hydrothermal conditions. Based on the experimental results, an advanced temperature-dependent stress-strain model for fly ash concrete under thermal steady state is proposed. Compared with previous models, the present model has the advantage of considering the variation of the curvature of stress-strain relationship with the increase in temperature. The results are not only a 
supplement to existing experimental data but also provide the basis for the continuous research on the fly ash concrete under thermal transient state.

Keywords: Fly ash concrete; Thermal exposure; High temperature; Steady state; Mechanical properties; Compressive stress-strain relationship

\section{Introduction}

Temperature-dependent mechanical properties of concrete play a significant role in structural engineering when thermal exposure has to be considered, like the fire resistance design of structures (catastrophes) $[1,2]$ and the design of nuclear reactor pressure vessels (service conditions) $[3,4,5]$. For the elastic analysis used in practice, the evolutions of elastic modulus and compressive strength with temperature are the basic required parameters, while in a more advanced analysis, the variation of plastic strain in compression should also be properly defined [6, 7]. However, unlike steel, concrete is a heterogeneous composite material whose constituents have considerable different thermomechanical properties. When the concrete is subject to sufficient heat, a series of physical and chemical reactions take place [8], which adds another dimension of complexities to its high temperature behavior.

The effect of increasing temperature on the mechanical properties of concrete has been investigated, but the specific testing methods adopted by different authors are different. In general, they could be distinguished according to testing at high temperature or after cooling down from thermal exposure [9]. The former is usually termed as "hot" test, while the latter is referred to as the residual test aiming at assessing its post-fire behavior. It should be mentioned that, in the cooling phase after thermal attack, there will be a further loss of compressive strength as a consequence of the continuing disintegration, which makes it hard to reach general conclusions since storage of concrete in cooling phase varies in different hydrothermal conditions 
[10]. Therefore, hot tests are necessary in evaluating the high temperature behavior of concrete.

Hot tests could be further categorized into the thermal-steady state test and the thermal transient state test. The concrete specimens in the steady state test were generally heated to achieve a uniform temperature field first and then they were loaded to failure, which is mainly used to obtain the stress-strain relations of concrete at different temperature levels [11]. In contrast, the specimens in the transient state test were first mechanically pre-loaded and then heated to failure, which is specially designed to measure the transient thermal creep (TTC) caused by pre-load [12]. Both of these two tests are typical representations of the possible thermomechanical conditions in concrete materials. Moreover, the thermal steady state test is the foundation of extracting TTC from the transient state test and for developing a complete constitutive model [13].

Nonetheless, due to the difficulty in apparatus, available studies on hot tests are much more limited than residual tests and only a few have managed measuring the complete stress-strain relations of concrete under thermal steady state. Most widely cited thermal steady state tests $[14,15]$ were performed from 1960 s to 1990 s and corresponding constitutive models and/or provisions were also established in that period. After that, it seems that the impetus to perform hot test on concrete has been decreased. However, the early studies used primarily ordinary Portland cement (OPC) as binders. There is a lack of test data and models on the effect of supplementary cementitious materials (SCM) on the stress-strain relations of concrete during thermal exposure, particularly when fly ash (FA) is used as the SCM.

FA is fine particles generated from the combustion of pulverized coal in electric power generation plants, which has been widely used as SCM in concrete for several decades [16]. As an industrial byproduct, FA is available in many countries and its 
recycling would bring significant economic and environmental benefits. These advantages have resulted in increased use of FA in concrete, especially in the ready-mixed concrete industry. Nonetheless, there is some concern on whether or not the FA would affect the fire safety of concrete material.

FA itself actually has little cementitious value, but if it is used together with OPC in making concrete the reactive silica in it will chemically react with calcium hydroxide $(\mathrm{CH})$ to form calcium-silicate-hydrate phases $(\mathrm{CSH})$ possessing cementitious properties. When concrete is heated above $100^{\circ} \mathrm{C}$ and in the presence of moisture, this process would be amplified, which could beneficially reduce the amount of $\mathrm{CH}$ and increase the mass of the solid skeleton of $\mathrm{CSH}$, resulting in a stronger and less permeable material [8]. In this way, the FA concrete, besides having an increased structural performance at ambient temperature, might also show a different performance at elevated temperatures. However, on the other side, the dehydration from the $\mathrm{CSH}$ also becomes significant above about $100^{\circ} \mathrm{C}$. The release of water would contribute the evaporation of moisture. With lower porosity and permeability in FA concrete, the vapor migration rate might be slower than the evaporation rate of pore water, which will lead the development of pore pressure [17]. The built-up of pore pressure, together with the reduction in strength due to the thermal decomposition of cement hydration products and the increase in the internal stresses caused by thermal gradient can cause severer damage in concrete. Therefore, the mechanical behavior of FA concrete at high temperature is complicated and difficult to predict.

Until now, only in the study of Diederichs [18], were FA concrete specimens tested under thermal steady state tests. However, Diederichs' work was aimed at investigating the mechanical properties of high-strength concrete (HSC) at elevated temperatures, rather than on the effect of FA. The compressive strength of the FA 
concrete samples in his study was higher than $100 \mathrm{MPa}$ and corresponding water/binder ratio is as low as 0.27 . Generally, HSC suffers pronounced higher rates of strength loss than normal-strength concrete (NSC) due to its denser structure and lower permeability $[19,20,21]$ which limit the ability of vapor in the concrete to escape and thus caused more destruction in cement matrix. The results of Diederichs showed that the strength loss of high-strength FA concrete (HSFC) differs a lot from NSC made from OPC and is more close to normal HSC without FA, which indicates that the effect of FA might be hidden and/or taken over by the low water/binder ratio in HSFC. Although FA itself could also yield similar pore pressure effect as described above, it might bring benefits from the accelerated and further activated chemical reactions. Therefore, it is necessary to perform tests on normal-strength FA concrete (NSFC) to avoid the overshadowing caused by HSC itself. After excluding the potential interference due to low water/binder ratio, the effect of FA on mechanical properties of concrete at high temperature would be clearer.

\section{Objectives}

Above-described study shows that the experimental research on FA concrete loaded under thermal steady state is incomplete. Meanwhile, the utilization of FA is still insufficient at present. There is still a large amount of FA were disposed in landfills every year, which has a negative impact on the environment. A more comprehensive verification of the compressive behavior of FA concrete during thermal exposure could help broadening its potential application in engineering.

The main aim of this research is to investigate the effect of partly replacing OPC with FA in manufacturing concrete on its mechanical properties during thermal exposure. Given the fact that the compressive mechanical properties of conventional OPC concrete without SCMs under thermal steady state have been well described, several previous studies are selected as reference group and the emphasis of our experiment is 
placed on normal-strength FA concrete (NSFC). A series of thermal steady state tests of the NSFC specimens are designed and performed, in which the water/binder ratio, aggregate type and FA replacement percentage are set to be in consistent with the reference experiments for the purpose of comparison. Also presented is the comparison between the experimental results and Eurocode [22] to examine the applicability of current code to concrete with FA. Based on the experimental results obtained, an advanced stress-strain model for FA concrete is proposed. Compared with existing models, the proposed model has an advantage of considering the variation of the curvatures of stress-strain relationships with increasing temperature. Finally, microstructures of the samples heated to different temperatures are examined by using SEM to investigate the thermal effect essentially on the organization of pore microstructures.

\section{Experimental details}

\subsection{Materials}

Table 1 gives the proportions and properties of concrete samples used in the present study. All samples were made from BS EN 197-1 CEM I type ordinary Portland cement. FA used in the investigation conforms to the requirements of dry BS EN 450-1 Type F (low calcium). The detailed chemical compositions of the cementitious materials are given in Table 2. The coarse aggregate was the crushed granite quarried from the Hingston Down quarry with the size of $10 \mathrm{~mm}$ and the fine aggregate was natural sand. The dimensions of the specimens were the cylinders of $50 \mathrm{~mm}$ diameter and $150 \mathrm{~mm}$ height, which gives a length/diameter ratio (slenderness) equal to 3. According to RILEM TC 200-HTC [23] such dimensions could avoid the end effect. The relatively small diameter used for the specimens was to minimize the inevitable structural effect during heating. All specimens were cast as described in ASTM C192 
and cured under polyethylene sheets in a laboratory environment for $24 \mathrm{hrs}$. The specimens were then demolded and moved into a tank of water for curing, which was used to provide $100 \% \mathrm{RH}$ and $20^{\circ} \mathrm{C}$ for 90 days. Before tests, the samples were oven dried at $30{ }^{\circ} \mathrm{C}$ for another 10 days, and the two end surfaces of them were polished to ensure that they are parallel and both perpendicular to the axis of the cylinder.

Tab.1 Concrete mix proportion and properties

\begin{tabular}{lc}
\hline Cement type-I $52.5, \mathrm{~kg} / \mathrm{m}^{3}$ & 351 \\
Fly ash (Class F), $\mathrm{kg} / \mathrm{m}^{3}$ & 117 \\
Coarse aggregate, crushed granite (maximum size $10 \mathrm{~mm}$ ), $\mathrm{kg} / \mathrm{m}^{3}$ & 710 \\
Fine aggregate, $\mathrm{kg} / \mathrm{m}^{3}$ & 910 \\
Water, $\mathrm{kg} / \mathrm{m}^{3}$ & 235 \\
Water $/ \mathrm{cement}$ ratio & 0.67 \\
Water/binder ratio & 0.5 \\
Plasticizer (BASF MasterPolyheed 410$), \mathrm{kg} / \mathrm{m}^{3}$ & 6.5 \\
Ambient temperature at casting, ${ }^{\circ} \mathrm{C}$ & 20 \\
\hline Compressive strength, $\mathrm{N} / \mathrm{mm}^{2}$ & 45 \\
Density, $\mathrm{kg} / \mathrm{m}^{3}$ & 2330 \\
\hline
\end{tabular}

Tab.2 Chemical composition of the binders

\begin{tabular}{|c|c|c|c|c|c|c|c|c|c|c|c|c|c|}
\hline \multirow{4}{*}{ Binders } & \multicolumn{13}{|c|}{ Composition (\%) } \\
\hline & \multirow{3}{*}{$\mathrm{SiO}_{2}$} & \multirow{3}{*}{$\mathrm{Al}_{2} \mathrm{O}_{3}$} & \multirow{3}{*}{$\mathrm{Fe}_{2} \mathrm{O}_{3}$} & \multirow{3}{*}{$\mathrm{CaO}$} & \multirow{3}{*}{$\mathrm{MgO}$} & \multirow{3}{*}{$\mathrm{SO}_{3}$} & \multirow{3}{*}{$\mathrm{TiO}_{2}$} & \multirow{3}{*}{$\mathrm{K}_{2} \mathrm{O}$} & \multirow{3}{*}{$\mathrm{Na}_{2} \mathrm{O}$} & \multirow{3}{*}{$\mathrm{Cl}$} & \multirow{3}{*}{$\begin{array}{l}\text { Loss on } \\
\text { Ignition }\end{array}$} & \multirow{3}{*}{$\begin{array}{l}\text { Free } \\
\mathrm{CaO}\end{array}$} & \multirow{3}{*}{$\begin{array}{l}\text { Insoluble } \\
\text { Residue }\end{array}$} \\
\hline & & & & & & & & & & & & & \\
\hline & & & & & & & & & & & & & \\
\hline Cement & 20.81 & 5.22 & 2.50 & 63.95 & 2.10 & 3.41 & - & 0.57 & 0.33 & 0.06 & 2.48 & 1.3 & 0.63 \\
\hline Fly ash & 62.81 & 21.02 & 11.63 & 4.25 & 1.70 & - & 1.35 & 2.06 & 2.23 & - & 2.11 & - & - \\
\hline
\end{tabular}

\subsection{Apparatus}

All tests were carried out on an instron-5582 testing machine as illustrated in Fig.1. Thermal exposure of concrete samples $(50 \mathrm{~mm}$ diameter $\times 150 \mathrm{~mm}$ length) was performed by using a split tube furnace with a chamber $(60 \mathrm{~mm}$ diameter $\times 300 \mathrm{~mm}$ 
length). The heating rate of the furnace was controllable, and the temperature distributions within the samples were monitored by the thermocouples attached on the surface and cast in the center of the specimens. The compressive displacement during mechanical loading was measured via a ceramic load extending placed outside of the furnace. The measurement was calibrated by a group of reference tests, in which the same load and heat as used in the tests were performed on the bottom loading rod without concrete specimen on it and the corresponding temperature and displacement were measured, which were then used to subtract the interference from the equipment.

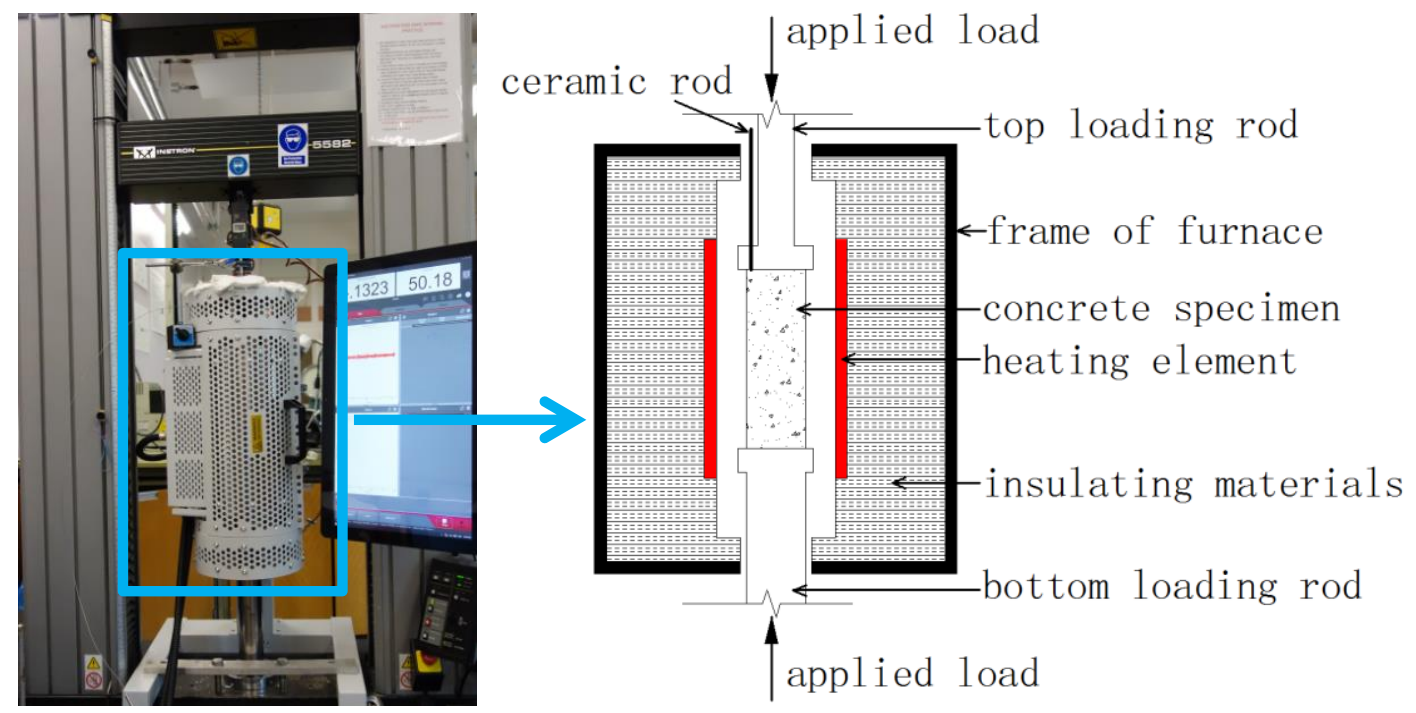

Fig.1. Experiment setup

\subsection{Test procedures}

All specimens were heated using the heating rate of $5{ }^{\circ} \mathrm{C} / \mathrm{min}$, according to the limitation of maximum heating rate recommended in RILEM TC 200-HTC, to corresponding target temperatures, as shown in Fig.2. During the heating period, moisture in the tested specimen was allowed to escape freely. After a further heating period of $1 \mathrm{hr}$ at the target temperature, which was found to be sufficient for reaching a nearly stable state in the specimen (the temperature difference between side surface and center is less than $2{ }^{\circ} \mathrm{C}$ ), the specimen was tested in a load control regime with a 
rate of $0.5 \mathrm{MPa} / \mathrm{s}$. In the whole process, temperatures, applied forces and uniaxial displacements of the sample were recorded simultaneously.

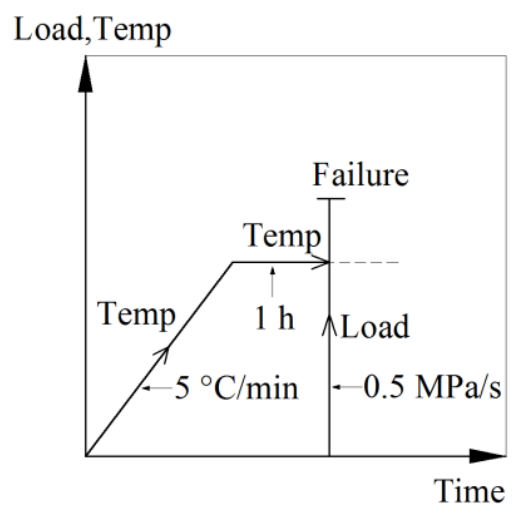

Fig.2. Heating and loading procedures

\section{Stress and deformation characteristics at high temperatures}

The compressive mechanical properties of conventional OPC concrete (without SCMs) at thermal steady state have been extensively studied and the results obtained by different researchers show a good agreement with each other when the samples used are made from the same aggregate type (calcareous/siliceous) and identical water/cement ratio. However, the other parameters, like the dimensions of sample, heating rate or some variations of raw materials, seem to have very limited impact on the results, as long as they vary within the practical range for NSC and RILEM TC 200-HTC. Therefore, several previous tests are selected as a reference group representing the normal-strength OPC concrete and the samples used in our tests are made from the same aggregate type (siliceous) and identical water/binder ratio $(0.5)$ for the purpose of comparison. The details are summarized in Table 3. For the purpose of comparison the results of HSFC provided by Diederichs [18] are also listed as a reference group.

Tab.3 Reference group

\begin{tabular}{|c|c|c|c|c|c|c|}
\hline Group & \multicolumn{5}{|c|}{ Reference } & Experiment \\
\hline Concrete type & \multicolumn{4}{|c|}{ OPC concrete (without SCMs) } & \multirow{2}{*}{\multicolumn{2}{|c|}{$\begin{array}{c}\text { Fly ash concrete } \\
\text { strength \& deformation }\end{array}$}} \\
\hline $\begin{array}{l}\text { Parameters to be } \\
\text { compared }\end{array}$ & \multicolumn{2}{|c|}{ strength } & \multicolumn{2}{|c|}{ deformation } & & \\
\hline Resources & $\begin{array}{c}\text { Abrams } \\
{[24]}\end{array}$ & $\begin{array}{c}\text { Malhotra } \\
\text { [25] }\end{array}$ & $\begin{array}{l}\text { Schneider } \\
\text { [9] }\end{array}$ & $\begin{array}{c}\text { Furumura } \\
\text { [26] }\end{array}$ & $\begin{array}{c}\text { Diederichs } \\
\text { [18] }\end{array}$ & Our tests \\
\hline
\end{tabular}




\begin{tabular}{c|c|c|c|c|c|c}
\hline Water/binder & 0.5 & 0.5 & - & 0.41 & 0.27 & 0.5 \\
\hline $\begin{array}{c}\text { Initial strength } \\
(\mathrm{MPa})\end{array}$ & 27 & 40 & - & 44 & 106.9 & 45 \\
\hline $\begin{array}{c}\text { Cementitious } \\
\text { materials }\end{array}$ & $100 \% \mathrm{OPC}$ & $100 \% \mathrm{OPC}$ & $100 \% \mathrm{OPC}$ & $100 \% \mathrm{OPC}$ & $\begin{array}{c}75 \% \mathrm{OPC} \\
25 \% \text { fly ash }\end{array}$ & $\begin{array}{c}75 \% \mathrm{OPC} \\
25 \% \text { fly ash }\end{array}$ \\
\hline Aggregate type & Siliceous & Siliceous & Siliceous & Siliceous & Siliceous & Siliceous \\
\hline
\end{tabular}

\subsection{Compressive strength}

The temperature-compressive strength relations are plotted in Fig.3, in which the compressive strength was normalized by the strength of unheated specimen, respectively. The blue solid line represents the results from our tests and each point on it is an average of at least two specimens at each temperature level. As can be seen, it shows a very similar trend as the dash lines representing the behavior of normal-strength concrete without SCMs. At the beginning, the compressive strength of NSFC remains unchanged to $200{ }^{\circ} \mathrm{C}$ and increases to about $105 \%$ at $300{ }^{\circ} \mathrm{C}$, which could be attributed to the further hydration under hydrothermal condition. Above that, the compressive strength decreases ceaselessly with elevated temperature due to the dehydration of $\mathrm{CSH}$. The decrease rate reaches the maximum value around $550{ }^{\circ} \mathrm{C}$ when the crystalline transformation from $\alpha$-quartz to $\beta$-quartz of aggregates may be taking place. In the whole range, the drop of compressive strength in NSFC keeps lower than that of NSC, which indicates that the further hydration of the reactive silica in FA during heating process does improve the high temperature performance of concrete. Given the replacement percentage of FA is only $25 \%$, the improvement is thus not prominent, but at least the positive effect of FA during thermal exposure can be confirmed. It could be concluded from the results shown in Fig. 3 that the Eurocode model [22], represented by the dot line in Fig.3, is quite safe when it is applied for FA concrete.

According to the comparison between the results from Abrams [24] and Malhotra [25], it could also be concluded that the variation of initial unheated strength seems to have little impact on the normalized value of compressive strength at different temperature 
levels. Nonetheless, above conclusion only applies to NSC. When it comes to HSFC, a very different variation of compressive strength with temperature could be observed. As illustrated in Fig.3, the chain line of HSFC drops much faster than the solid curve of NSFC at the early stage, which is the consequence of the denser microstructure and corresponding higher pore pressure in HSFC. It could be inferred that there are critical values for the parameters that could yield condensation in cement paste, like water/binder ratio or replacement percentage of FA. Beyond the critical values, highly condensed microstructure would be produced in concrete and results in destructive pore pressure under thermal exposure. On the other hand, the difference between NSFC and HSFC decreases with the increasing temperature. When the temperature reaches to $800{ }^{\circ} \mathrm{C}$, they are very close to each other, which indicates that the compressive strength at relatively high temperature (beyond $600{ }^{\circ} \mathrm{C}$ ) is almost independent of pore pressure. The variation in aggregates might be the main contribution in this phase.

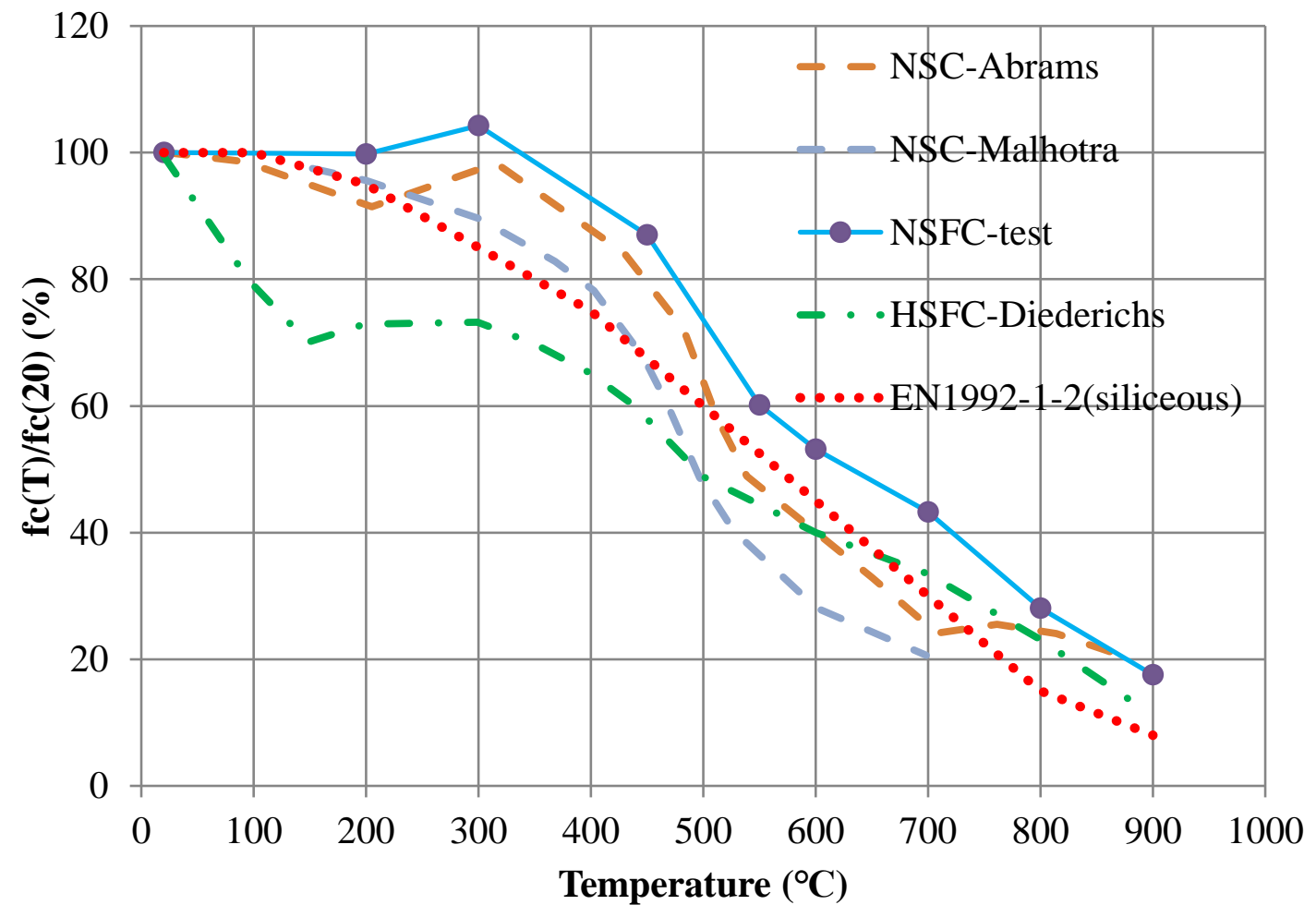


Fig.3. Normalized compressive strength at different temperatures

\subsection{Peak strain at compressive strength}

The peak strain at compressive strength is a key deformation characteristic in evaluating the plastic strain of concrete, but it is hard to be determined at high temperature due to the difficulty in measurement. Thus, there are few available results on it. Fig.4 shows that, the strains at peak stress point of NSC and NSFC, tested by Schneider [9], Furumura [26] and ourselves, are almost identical to each other before $300{ }^{\circ} \mathrm{C}$ and only slight difference is observed afterwards, which indicates that FA has no significant influence on the strain at peak stress point. The thermal incompatibility between aggregate and cement paste might be the main contribution and, in that case the aggregate type should be the decisive factor. From the common trend of these three curves one could conclude that the strain at peak stress point keeps approximately unchanged until $200{ }^{\circ} \mathrm{C}$ and increases rapidly above that. In contrast, the strain at peak stress point of HSFC increases obviously slower than that of NSFC for temperatures between $200{ }^{\circ} \mathrm{C}$ and $450{ }^{\circ} \mathrm{C}$, suggesting a more brittle behavior, which could be attributed to its denser structure and corresponding higher loss of compressive strength in that temperature range. Another interesting result could be observed from Fig.5 is that the temperature-strain (at peak stress point) relationship in Eurocode is much higher than those of all other experiment results. This is because the strain at peak stress point in Eurocode has implicitly included an extra strain component called transient thermal creep (TTC) resulted from pre-fire load [12]. This implicit inclusion is safe and conservative in many cases, but it might yield wrong estimation of the deformation in concrete when the pre-fire load varies during the thermal exposure. For an advanced analysis, TTC should be calculated explicitly and Eurocode may not be applicable at that situation $[27,28]$. 


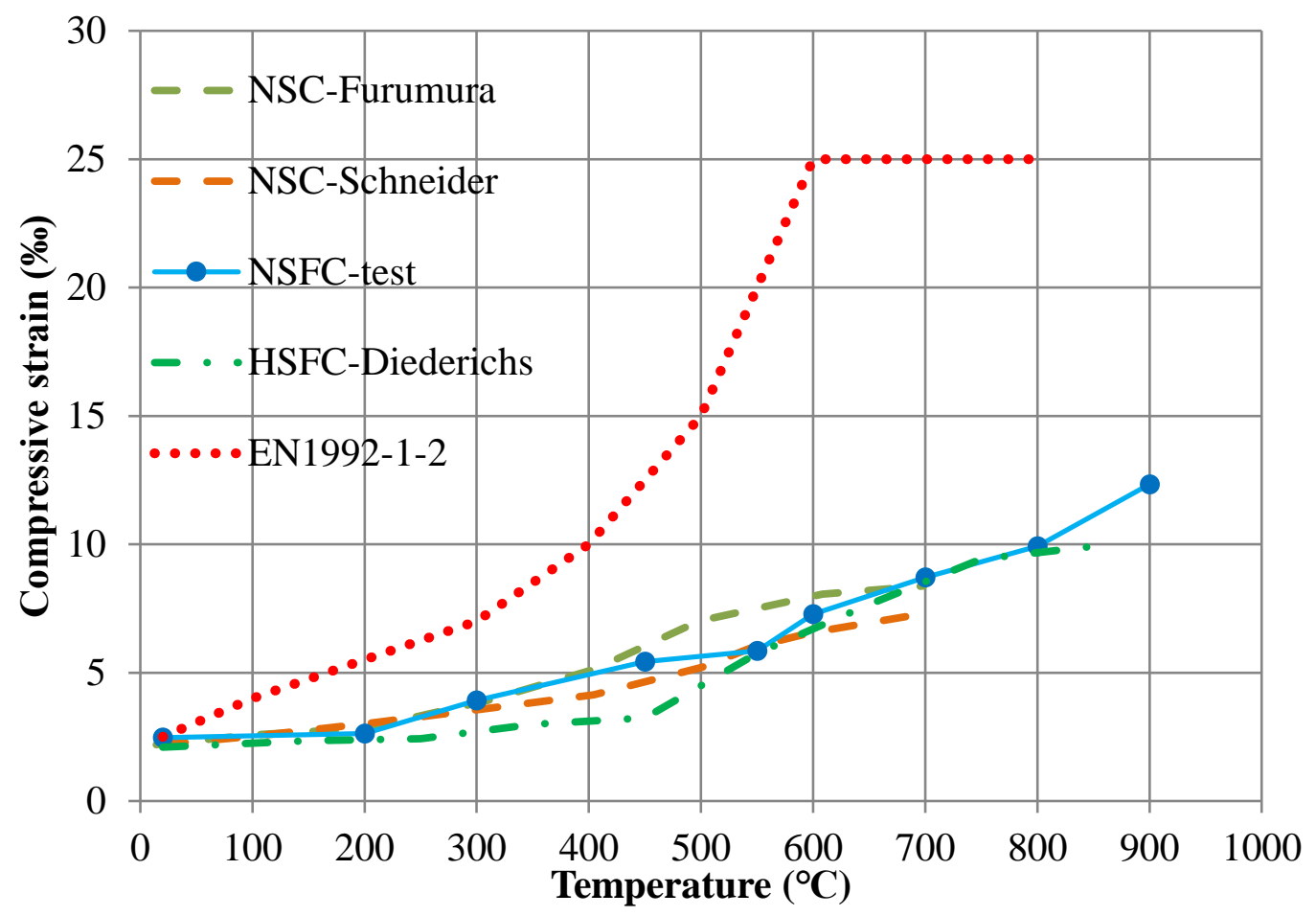

Fig.4. Strain at peak stress point at different temperatures

\subsection{Modulus of elasticity in compression}

As discussed above, the compressive strength is decreasing while the strain at peak stress point is increasing with elevated temperature, which means that concrete is softening under thermal exposure. Therefore, it is also important to evaluate the variation of its stiffness, represented by the temperature-dependent elastic modulus. For the purposes of comparison, the modulus of elasticity is taken as the secant modulus at $30 \%$ of the compressive strength from the experimentally obtained stressstrain curve. As a deformation characteristic, the temperature-dependent variation of elastic modulus is also mainly controlled by the aggregate type and hardly influenced by the partly replaced FA, similar to the behavior of the strain at peak stress point as discussed above. As illustrated in Fig.5, the decrease of the modulus of elasticity of concrete with increasing temperature generally exceeds the decrease of its strength, and the curves for different concretes are in good agreement with each other since they are all made from siliceous aggregate. The difference exists between NSFC and HSFC at around $200{ }^{\circ} \mathrm{C}$, which could be ascribed to the variation in their pore 
pressure at that phase.

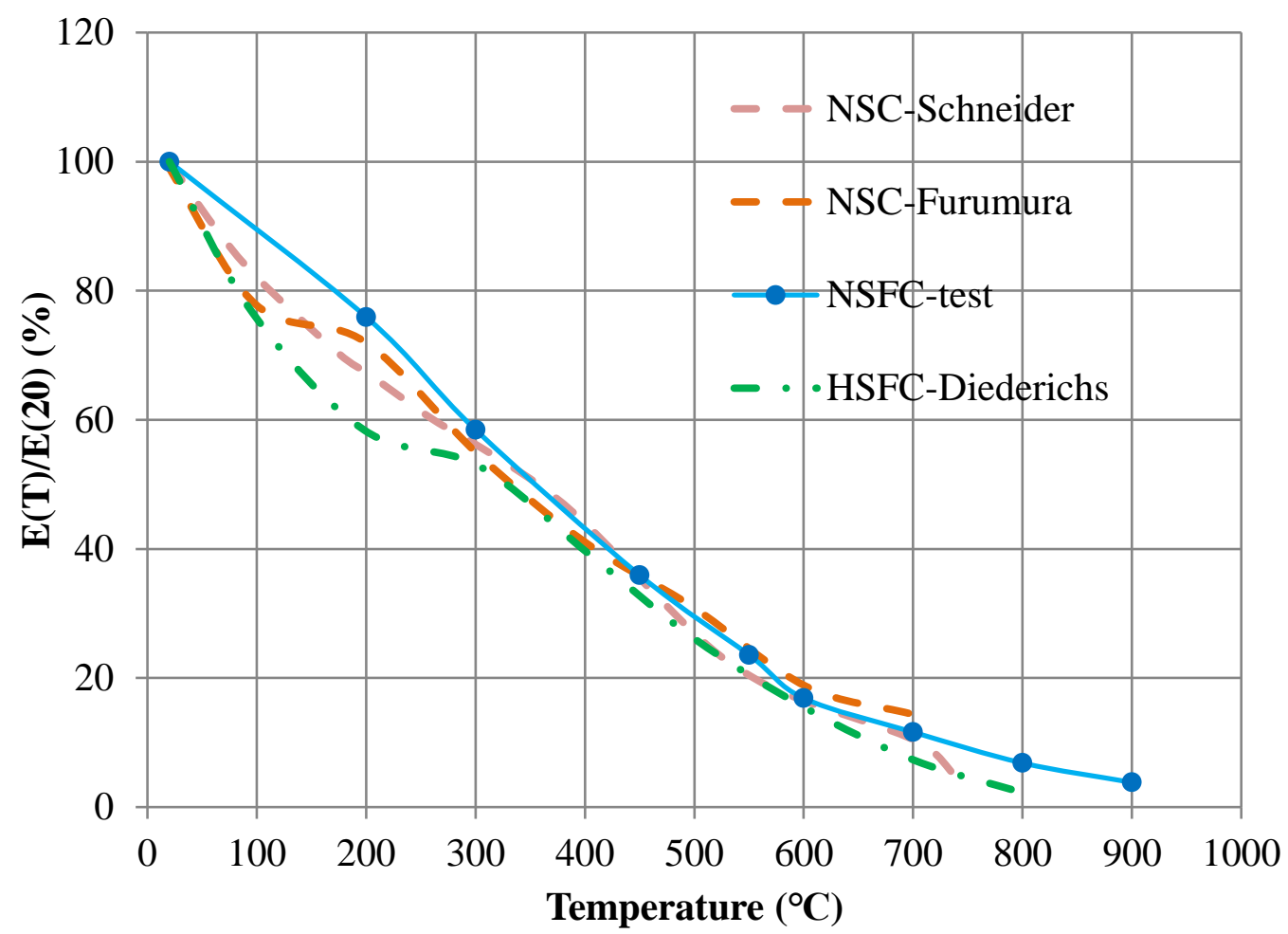

Fig.5. Normalized elastic modulus at different temperatures

\section{Development of an advanced stress-strain model}

\subsection{Determination of the basic equation}

Table 4 provides three most widely accepted stress-strain models (ascending branch) that have been adopted in literature for concrete at high temperatures. However, all these three models assume the curvatures of the stress-strain relations keep unchanged when the temperature increases. As illustrated in Fig.6, the dash lines represent the normalized experimental stress-strain relations at different temperatures, while the solid lines are calculated by using the models shown in Table 4. It is evident that the curvatures of experimentally obtained stress-strain relations vary with temperature, while the three theoretical models are incapable of capturing this phenomenon since their curvatures are constant. This is an important characteristic but has been frequently ignored. In the present study, Eq.(4) proposed by Popovics [29] is selected 
as the basic equation since it has the advantage of incorporating a parameter " $n$ " to control the curvatures of the curves.

Tab.4 Constitutive models for concrete in compression at high temperatures

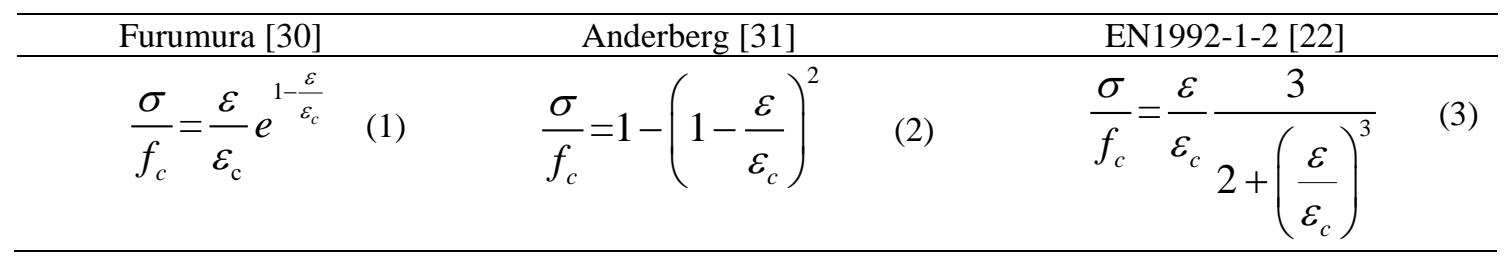

$$
\frac{\sigma}{f_{c}}=\frac{\varepsilon}{\varepsilon_{c}} \frac{n}{n-1+\left(\frac{\varepsilon}{\varepsilon_{c}}\right)^{n}}
$$

where $\sigma, \varepsilon$ are the instantaneous stress and strain, respectively; $f_{c}$ is the compressive strength of unheated concrete; $\varepsilon_{c}$ is the strain at peak stress point at compressive strength of unheated concrete; $\mathrm{n}$ is a parameter related to the curvature of the stress-strain relationship of concrete at ambient temperature.

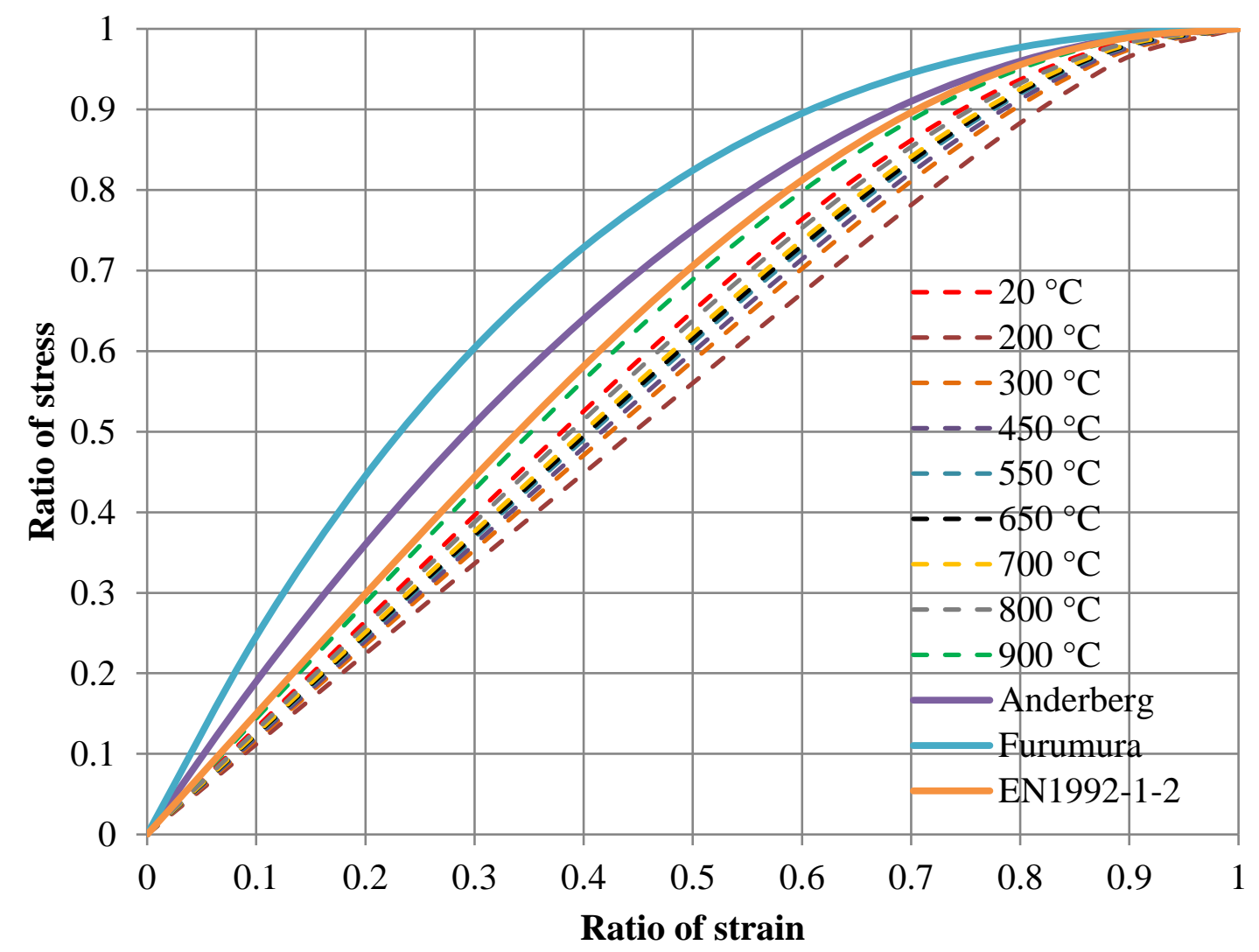


Fig.6. Variation of normalized stress-strain relations and corresponding curvatures at different temperatures

\subsection{Curvatures of stress-strain relations}

By applying Eq.(4) to the experimental stress-strain data, the parameter " $n$ " at different temperature levels could be determined. Fig.7 shows that parameter "n" increases to 9 at $200{ }^{\circ} \mathrm{C}$ and then drops quickly to 6.6 at around $300{ }^{\circ} \mathrm{C}$. After that, the decrease rate slows down. When the heating terminates at $900{ }^{\circ} \mathrm{C}$, it drops back to approximately the initial value. The higher value of $n$ means that the stress-strain response is more linear. Fig.6 shows that the experimentally obtained curves are more linear than those of the previous OPC concrete models, which indicates that $\mathrm{n}$ has a higher value and there is less plastic strain in the FA concrete. This phenomenon could be ascribed to the increased skeleton of CSH caused by the reaction between FA and $\mathrm{CH}$. The rapid increase of $\mathrm{n}$ at early stage is a consequence of the amplification of the reaction with increased temperature, while the decrease at latter stage might be caused by the thermally induced micro-cracks in cement paste and the decomposition of CSH.

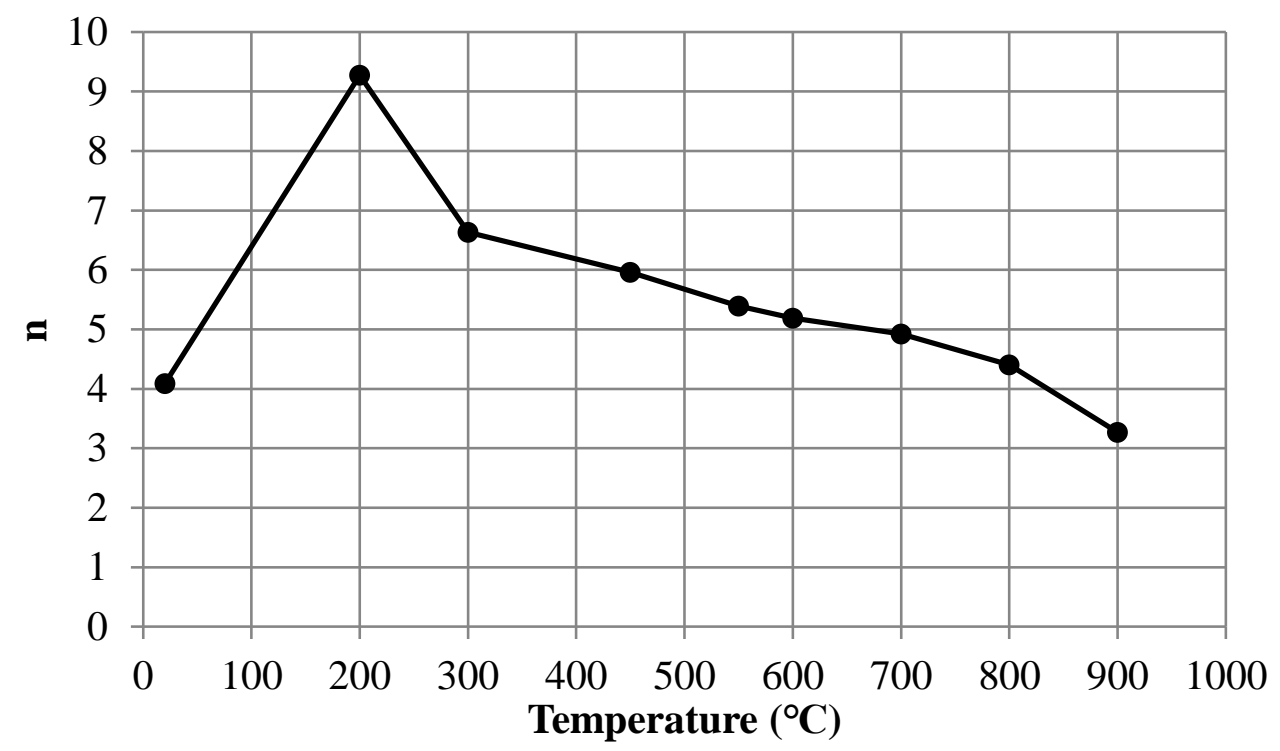

Fig.7. Parameter $\mathrm{n}$ at different temperatures 


\subsection{Advanced stress-strain model}

With the knowledge of the basic stress-strain equation, for example Eq.(1) given by Popovics [29], and the variation of compressive strength, peak strain and curvature parameter $\mathrm{n}$ as mentioned above, a complete temperature-dependent stress-strain model could be proposed as follows,

$$
\frac{\sigma}{f_{c}(T)}=\frac{\varepsilon}{\varepsilon_{c}(T)} \frac{n(T)}{n(T)-1+\left(\frac{\varepsilon}{\varepsilon_{c}(T)}\right)^{n(T)}}
$$

where $f_{c}(T)$ is the compressive strength at temperature $\mathrm{T} ; \varepsilon_{c}(T)$ is the strain at peak stress point at temperature $\mathrm{T} ; n(T)$ is the curvature parameter at temperature $\mathrm{T}$. To simplify the model, the variation of the three temperature-dependent parameters could be represented by linear relations that fit original curves reasonably, as demonstrated in Fig.8.

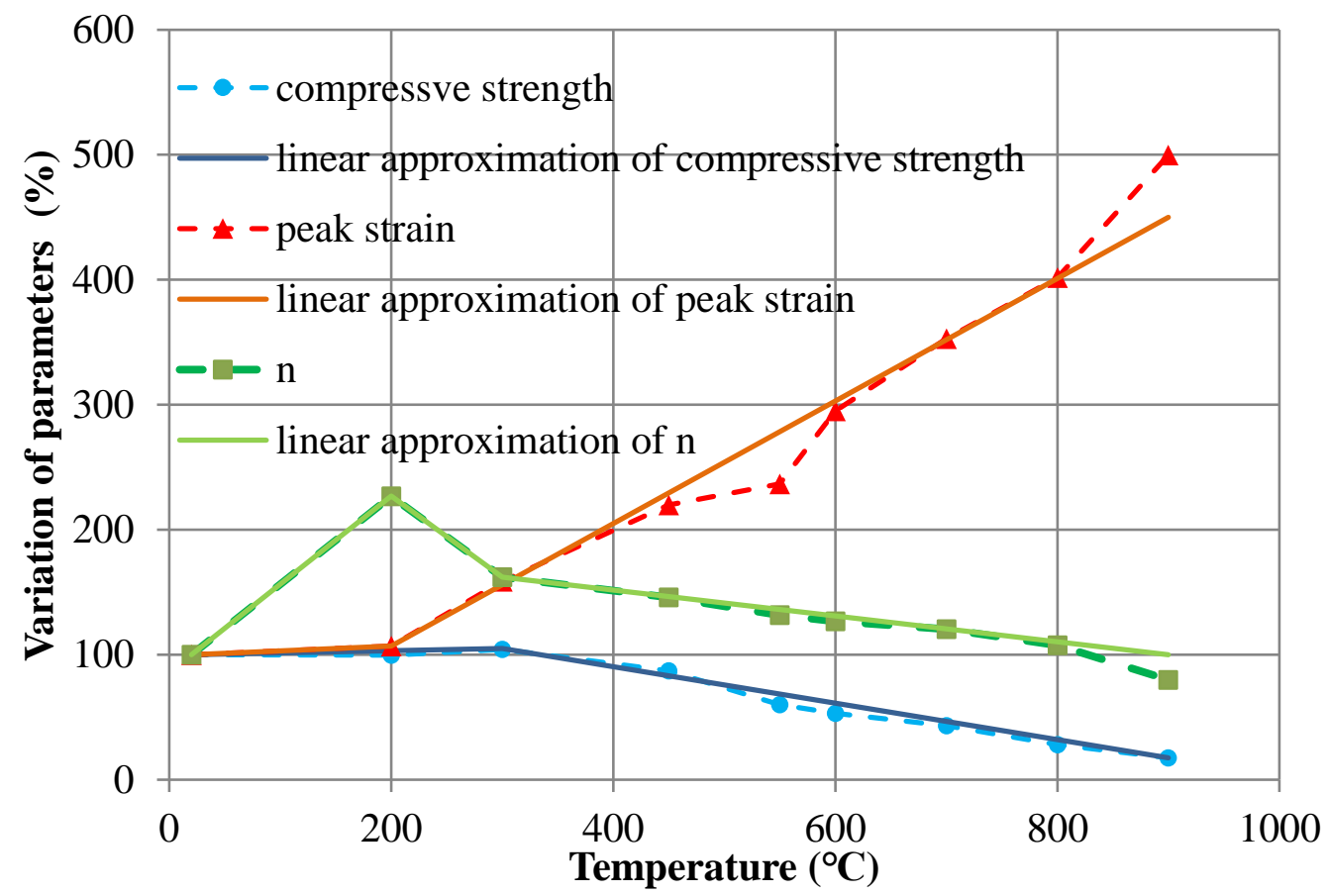

Fig.8. Linear approximation used for three decisive parameters

In this way, the complete compressive stress-strain model could be incorporated with 
Eqs.(6)-(8) to achieve a simpler solution in analysis.

$$
\begin{gathered}
f_{c}(T)= \begin{cases}f_{c, 20} \times\left(0.996+2 \times 10^{-4} \times T\right), & 20 \leq T \leq 300 \\
f_{c, 20} \times\left(1.4875-1.458 \times 10^{-3} \times T\right), & 300 \leq T \leq 900\end{cases} \\
\varepsilon_{c}(T)= \begin{cases}\varepsilon_{c, 20} \times\left(0.9922+3.89 \times 10^{-4} \times T\right), & 20 \leq T \leq 200 \\
\varepsilon_{c, 20} \times\left(0.09+4.9 \times 10^{-3} \times T\right), & 200 \leq T \leq 900\end{cases} \\
n(T)= \begin{cases}n_{20} \times\left(0.8589+7.056 \times 10^{-3} \times T\right), & 20 \leq T \leq 200 \\
n_{20} \times\left(3.57-6.5 \times 10^{-3} \times T\right), & 200 \leq T \leq 300 \\
n_{20} \times\left(1.93-1.033 \times 10^{-3} \times T\right), & 300 \leq T \leq 900\end{cases}
\end{gathered}
$$

\subsection{Verification of proposed model}

Fig.9 shows the comparison between the experimentally obtained stress-strain curves, represented by the red dot points, and those calculated from the proposed model, in which the black dash lines represent the results calculated by Eq.(5) with parameters directly measured from experiments and the light blue solid lines represent the results calculated by using simplified model Eq.(5)-(8). It is obvious from the comparisons that the theoretical model behaves excellently, whereas the simplified model differs marginally from the experimental data but with generally acceptable errors. This indicates that, when the model is adopted, the parameters incorporated could be determined by either way (measured value or simplified relations), depending on the expected efficiency and accuracy specifically. 


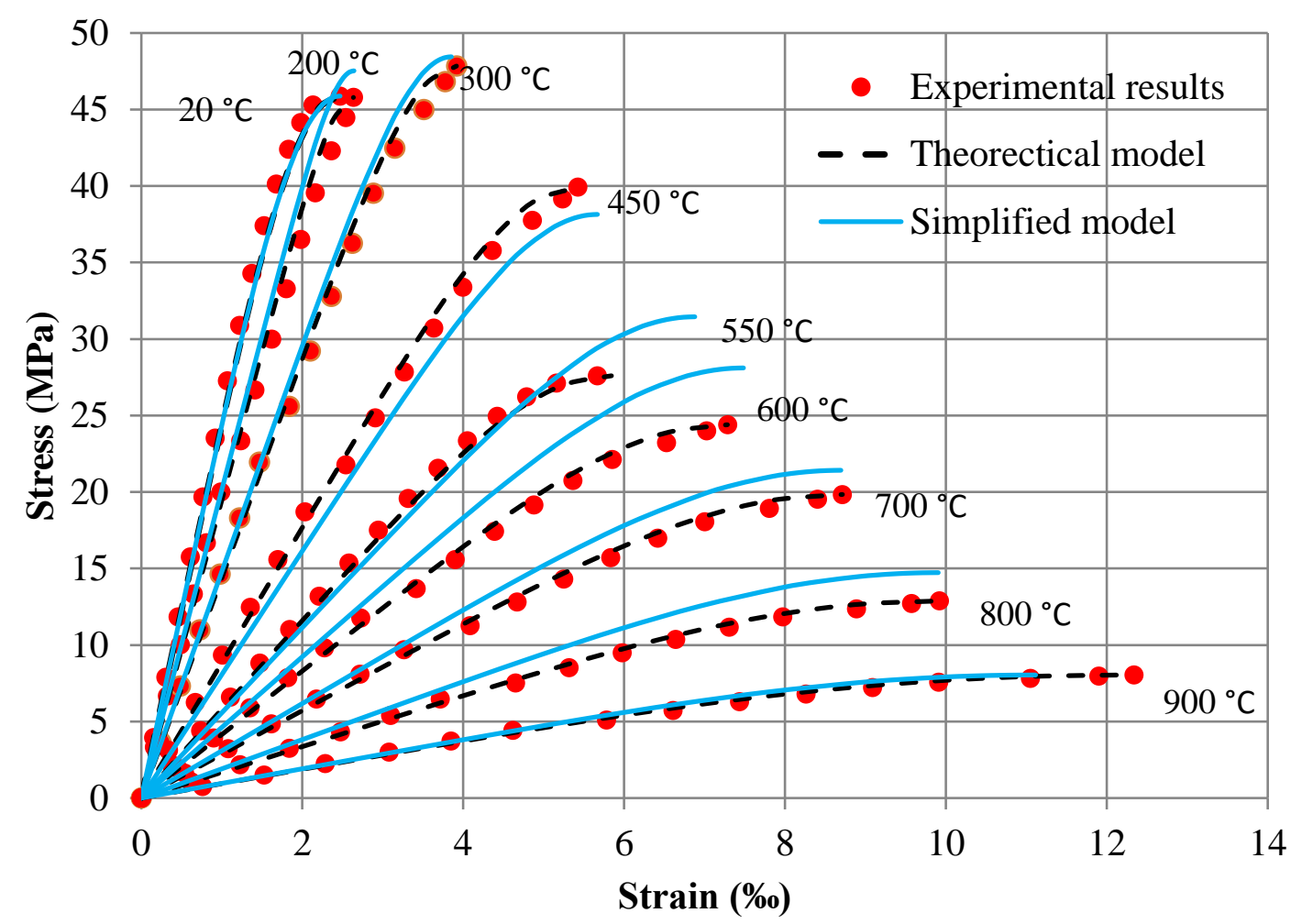

Fig.9. Comparison of experimental stress-strain relations with proposed model

\section{Microstructure imaging}

The microstructures of crushed powder samples of the specimens under different temperatures were examined by using SEM techniques to understand the thermal effect on the change of micro-structure organization of FA concrete. As illustrated in Fig.10a, some unreacted FA particles were observed in the unheated specimen. In contrast, Fig. $10 \mathrm{~b}$ shows that after the specimens were heated to $450{ }^{\circ} \mathrm{C}$, the unreacted particles disappeared due to the reaction between the FA and calcium hydroxide, which is in consistent with what was reported in literature as mentioned in introduction section. Moreover, the cement paste is reasonably dense and compact at ambient temperature. However, with increasing temperature, the microstructure of the cement matrix seems to have undergone significant changes. At $450{ }^{\circ} \mathrm{C}$, some discrete pores developed due to the vapor migration and increased pore pressure. After the temperature increased to $550{ }^{\circ} \mathrm{C}$, aggregate begin to rapidly expand since it is 
approaching to the temperature for $\alpha-\beta$ phase transformation [32]. The sharp increase of expansion in aggregate at around $550{ }^{\circ} \mathrm{C}$ is opposite to the shrinkage of cement paste, resulting in severe damage and cracks at the interface between aggregates and adjacent cement paste, which is the reason for the observed maximum degradation rate of compressive strength at this temperature in our experiments. At last, when the temperature hits $700{ }^{\circ} \mathrm{C}$, the $\mathrm{CSH}$ phase has decomposed and the cement matrix has turned into a loose white material that is very porous and weak. The corresponding deterioration of mechanical properties of concrete at this temperature is very obvious as illustrated in Fig.9.

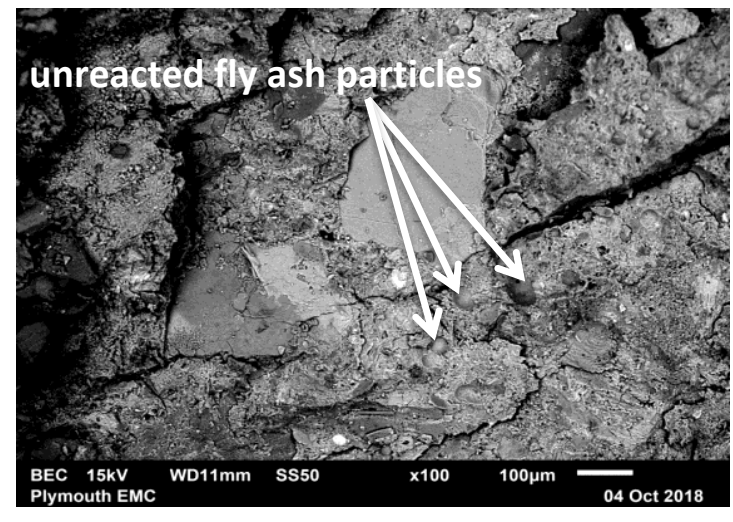

a. $20^{\circ} \mathrm{C}$

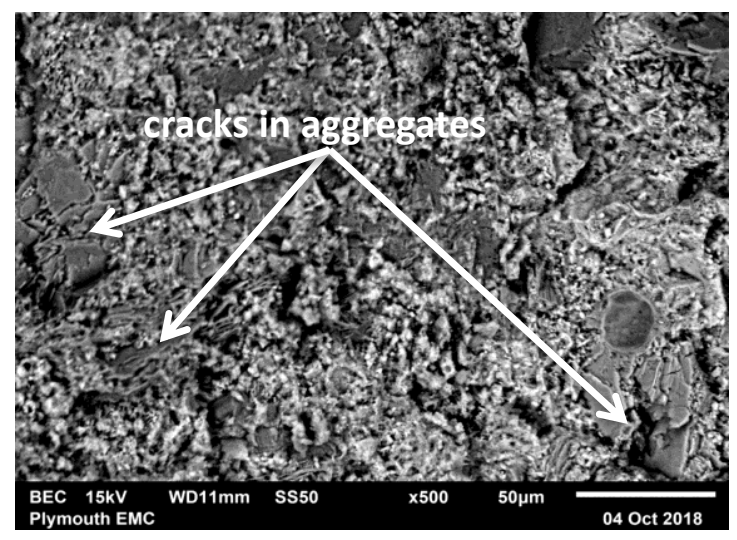

c. $550^{\circ} \mathrm{C}$

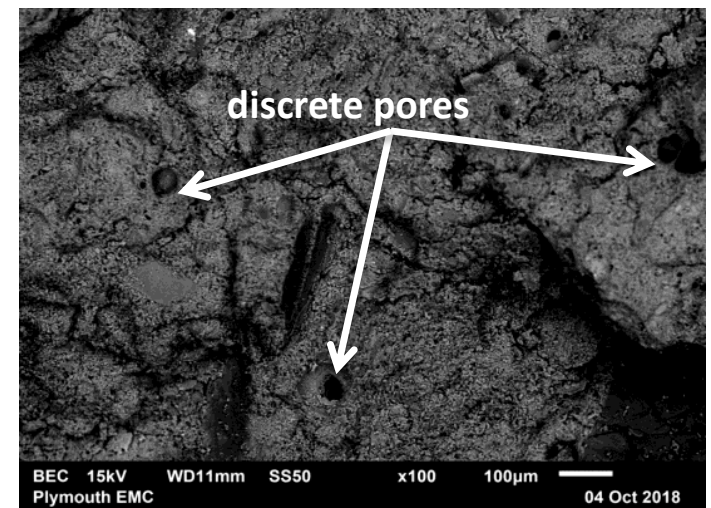

b. $450{ }^{\circ} \mathrm{C}$

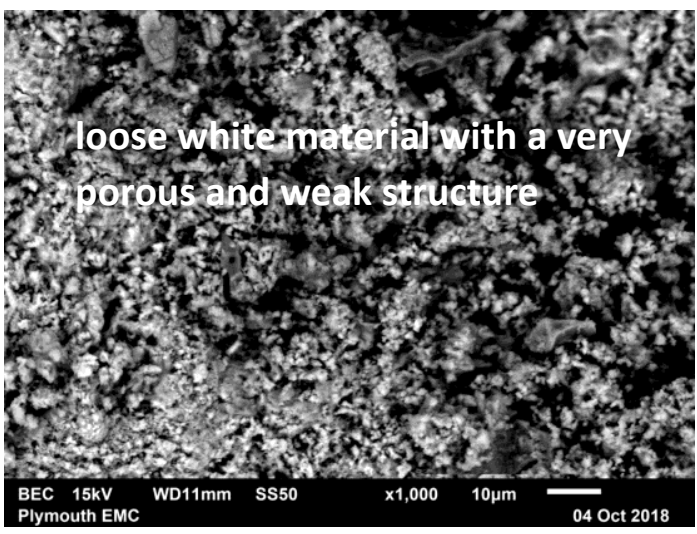

d. $700{ }^{\circ} \mathrm{C}$

Fig.10. Microstructures of crushed FA concrete under different temperatures 


\section{Conclusions}

The paper has presented an experimental study on the mechanical properties of fly ash concrete during thermal exposure. The tests were carried out on an apparatus specially designed for studying "hot" mechanical properties of concrete materials. The results presented include the compressive strength, strain at peak stress point, Young's modulus, and stress-strain relation at temperature ranging from ambient to $900{ }^{\circ} \mathrm{C}$. From the present results the following conclusions can be drawn:

1) $25 \%$ replacement of cement with FA in concrete hardly influences its deformation characteristics at high temperatures, but the temperature-dependent compressive strength would be enhanced due to the further reaction between FA and calcium hydroxide under hydrothermal conditions.

2) Eurocode EN1992-1-2 seems to be safe to be applied to normal strength concrete with $25 \%$ replacement of FA as SCM. However, the strain at peak stress point recommended in EN1992-1-2 has implicitly included the transient thermal creep, which should be explicitly calculated using the advanced analysis method.

3) Porosity of cement paste has a significant influence on the mechanical properties of concrete at high temperatures, especially at early stage of thermal exposure (before $500{ }^{\circ} \mathrm{C}$ ). There might be a critical value for the replacement percentage of FA, which could lead the increase of solid skeleton of cement paste and potential destructive pore pressure during heating. Therefore, the higher replacement percentage of FA in cement should be further verified.

4) The shape of stress-strain relationship, represented by the curvature of the curve, would vary with temperature. Adding FA into concrete would make it behave more linearly and reduce its plasticity due to the increased skeleton of CSH caused by the 
hydration of FA and the related amplification during heating.

5) A complete temperature-dependent stress-strain model for FA concrete in compression has been formulated and verified. Compared with previous models, the present model has the advantage of incorporating a parameter $n(T)$ to consider the variation of the curvature.

\section{Acknowledgement}

The authors would like to acknowledge the support received from the European Commission Research Executive Agency via a Marie Skłodowska - Curie Research and Innovation Staff Exchange project (689857-PRIGeoC-RISE-2015). The first author would also like to thank the China Scholarship Council and University of Plymouth for providing him a studentship for his $\mathrm{PhD}$ study in University of Plymouth.

\section{Declaration of interest}

None

\section{References}

[1] X.X. Zha, FE analysis of fire resistance of concrete filled CHS columns, J Constr Steel Res. 59 (2003) 769-779.

[2] V. Kodur, T. Wang, F. Cheng, Predicting the fire resistance behaviour of high strength concrete columns, Cement Concrete Comp. 26 (2004) 141-153.

[3] U. Schneider, U. Diederichs, C. Ehm, Effect of temperature on steel and concrete for PCRV's, Nucl Eng Des. 67 (1982) 245-258.

[4] H. Kallel, H. Carré, C. La Borderie, B. Masson, N.C. Tran, Effect of temperature and moisture on the instantaneous behaviour of concrete, Cement Concrete Comp. 
80 (2017) 326-332.

[5] H. Kallel, H. Carré, C. Laborderie, B. Masson, N. Cuong Tran, Evolution of mechanical properties of concrete with temperature and humidity at high temperatures, Cement Concrete Comp. 91 (2018) 59-66.

[6] X.X. Zha, Three-dimensional non-linear analysis of reinforced concrete members in fire, Build Environ. 38 (2003) 297-307.

[7] C.Y. Wan, X.X. Zha, J.B.M. Dassekpo, Analysis of axially loaded concrete filled circular hollow double steel tubular columns exposed to fire, Fire Safety J. 88 (2017) $1-12$.

[8] G. Khoury, C. Majorana, F. Pesavento, B. Schrefler, Modelling of heated concrete, Mag Concr Res. 54 (2002) 77-101.

[9] U. Schneider, Concrete at High-Temperatures - a General-Review, Fire Safety J. 13 (1988) 55-68.

[10] G.A. Khoury, B.N. Grainger, P.J. Sullivan, Transient thermal strain of concrete: literature review, conditions within specimen and behaviour of individual constituents, Mag Concr Res. 37 (1985) 131-144.

[11] W.D.A. Rickard, G.J.G. Gluth, K. Pistol, In-situ thermo-mechanical testing of fly ash geopolymer concretes made with quartz and expanded clay aggregates, Cement Concrete Res. 80 (2016) 33-43.

[12] G. Torelli, P. Mandal, M. Gillie, V.-X. Tran, Concrete strains under transient thermal conditions: A state-of-the-art review, Eng Struct. 127 (2016) 172-188.

[13] U. Schneider, M. Schneider, An advanced transient concrete model for the determination of restraint in concrete structures subjected to fire, J Adv Concr Technol. 7 (2009) 403-413.

[14] L.Y. Li, J. Purkiss, Stress-strain constitutive equations of concrete material at elevated temperatures, Fire Safety J. 40 (2005) 669-686.

[15] M. Youssef, M. Moftah, General stress-strain relationship for concrete at elevated temperatures, Eng Struct. 29 (2007) 2618-2634.

[16] V. Malhotra, Fly ash, slag, silica fume, and rice husk ash in concrete: A review, Concrete International. 15 (1993) 23-28. 
[17] V. Kodur, Properties of concrete at elevated temperatures, ISRN Civil Engineering. 2014 (2014).

[18] U. Diederichs, U. Jumppanen, V. Penttala, Material properties of high strength concrete at elevated temperatures, 13th Congress of International Association for Bridge and Structural Engineering IABSE, Helsinki, Finland, (1988)489-494.

[19] Y. Wang, I. Burgess, F. Wald, M. Gillie, Performance-based fire engineering of structures, CRC Press, London, 2012.

[20] F.P. Cheng, V. Kodur, T.-C. Wang, Stress-strain curves for high strength concrete at elevated temperatures, J Mater Civil Eng. 16 (2004) 84-90.

[21] Y. Fu, Y. Wong, C. Poon, C. Tang, Stress-strain behaviour of high-strength concrete at elevated temperatures, Mag Concr Res. 57 (2005) 535-544.

[22] Eurocode2: Design of concrete structures-Part 1-2: General rules-Structural fire design, European Prestandard, Brussels, 1995.

[23] R.T.C. 200-HTC, Recommendation of RILEM TC 200-HTC: mechanical concrete properties at high temperatures - modelling and applications, Mater Struct. 40 (2007) 841-853.

[24] M.S. Abrams, Compressive Strength of Concrete at Temperatures to 1600F, Temperature and Concrete, SP-25, American Concrete Institute, Detroit,(1971) 33-58.

[25] H.L. Malhotra, The effect of temperature on the compressive strength of concrete, Mag Concr Res. 8 (1956) 85-94.

[26] T. Abe, F. Furumura, K. Tomatsuri, K. Kuroha, I. Kokubo, Mechanical properties of high strength concrete at high temperatures, J Struct Constr Eng. 515 (1999) 163-168.

[27] T. Gernay, J.M. Franssen, A formulation of the Eurocode 2 concrete model at elevated temperature that includes an explicit term for transient creep, Fire Safety J. 51 (2012) 1-9.

[28] T. Gernay, Effect of transient creep strain model on the behavior of concrete columns subjected to heating and cooling, Fire Technol. 48 (2012) 313-329.

[29] S. Popovics, A numerical approach to the complete stress-strain curve of concrete, Cement Concrete Res. 3 (1973) 583-599. 
[30] J. Purkiss, L.Y. Li, third ed., Fire safety engineering design of structures, CRC Press, London, 2013.

[31] Y. Anderberg, S. Thelandersson, Stress and deformation characteristics of concrete at high temperatures, Lund Institute of Technology, Lund, 1976.

[32] K.D. Hertz, Concrete strength for fire safety design, Mag Concr Res. 57 (2005) 445-453. 